\title{
BMJ Open Do medical students recognise the deteriorating patient by analysing their vital signs? A monocentric observational study based on the National Early Warning Score 2
}

David Alexander Christian Messerer (D) , ${ }^{1,2}$ Michael Fauler, ${ }^{3}$ Astrid Horneffer, ${ }^{4}$ Achim Schneider, ${ }^{4}$ Oliver Keis, ${ }^{4}$ Lea-Marie Mauder, ${ }^{5}$ Peter Radermacher ${ }^{1}$

To cite: Messerer DAC, Fauler M, Horneffer A, et al. Do medical students recognise the deteriorating patient by analysing their vital signs? A monocentric observational study based on the National Early Warning Score 2. BMJ Open 2021;11:e044354. doi:10.1136/ bmjopen-2020-044354

- Prepublication history for this paper is available online. To view these files, please visit the journal online (http://dx.doi. org/10.1136/bmjopen-2020044354).

Received 31 August 2020 Revised 09 January 2021 Accepted 18 January 2021

\section{D) Check for updates}

(C) Author(s) (or their employer(s)) 2021. Re-use permitted under CC BY-NC. No commercial re-use. See rights and permissions. Published by BMJ.

For numbered affiliations see end of article.

\section{Correspondence to} Dr David Alexander Christian Messerer;

david.messerer@uni-ulm.de

\section{ABSTRACT}

Objective Assessment of the expertise of medical students in evaluating vital signs and their implications for the current risk of a patient, an appropriate monitoring frequency, and a proper clinical response.

Methods 251 second-year and 267 fifth-year medical students in a curriculum consisting of 6 years of medical school at UIm University, Germany, were interviewed in a paper-based questionnaire. The students were asked to rate their proficiency in interpreting vital signs and to give pathological thresholds of vital signs. Based on the National Early Warning Score 2 (NEWS2), nine vital signs of fictional patients were created and students were asked to comment on their clinical risk, to set an appropriate monitoring frequency as well as a clinical response. Results Interviewing medical students regarding each vital sign individually, the students indicated a pathological threshold in accordance with the NEWS2 for respiratory rate, temperature, and heart rate. By contrast, inappropriate pathological limits were given regarding oxygen saturation and systolic blood pressure. Translating the vital signs into nine fictional patients, fifth-year medical students overall chose an appropriate response in $78 \%$ (67\%-78\%, median $\pm \mid Q R)$. In detail, fifth-year students successfully identified patients at very high or low risk and allocated them accordingly. However, cases on the edge were often stratified inappropriately. For example, a fictional case with vital signs indicating a surging sepsis was frequently underappreciated (48.5\%) and allocated to an insufficient clinical response by fifth-year students. Conclusions Recognising the healthy as well as the deteriorating patient is a key ability for future physicians. NEWS2-based education might be a valuable tool to assess and give feedback on student's knowledge in this vital professional activity.

\section{INTRODUCTION}

Vital signs are a universal, interdisciplinary and interprofessional language, which are a pivotal component of communicating the current status of a patient. Furthermore, their measurement is non-demanding to patients, feasible to master and can be performed with reasonable human resources without requiring elaborate
Strengths and limitations of this study

- In this study, the authors report about the ability of medical students to stratify patient cases based on their vital signs as an important surrogate of the individual risk of a patient.

- For this purpose, nine fictional cases were created based on the well-established National Early Warning Score 2.

- Over 200 junior and senior medical students were interviewed; however, these were limited to a single-centre study.

- This study is limited in that it presented vital signs in a paper-based format, thus lacking additional information that would be available at the patient's bedside.

equipment. Therefore, the acquisition of vital signs can be performed repetitively, being an attractive surrogate for the current clinical risk of a patient. In this context, the proper assessment of vital signs and their evaluation concluding in an adequate response to clinical deterioration are crucial for optimal patient care and as such constitute an important professional activity. For example, it is estimated that among preventable deaths, around $30 \%$ are attributed to insufficient clinical monitoring. ${ }^{1}$ In order to facilitate the proper assessment of vital signs, several 'early warning scores' (EWSs) have been developed and widely validated..$^{2-4}$ Most clinical warning scores consist of an aggregate score cumulating several vital signs and other factors. In a bestcase scenario, EWSs ensure that medical professionals successfully recognise critical patients early and provide them with a rapid referral and a prompt rescue, thus resulting in an improvement of patient outcome if applied properly. ${ }^{5}$

In the present work, we (1) interview junior and senior medical students regarding their 
proficiency to assess and stratify vital signs, (2) propose a framework of nine fictional patients, and (3) report about the students' success and failures to recognise and allocate these fictional patients to a proper clinical response.

\section{MATERIALS AND METHODS}

To generate vital signs of fictional patients with different clinical risks, several warning scores were assessed. By critical appreciation of the available literature related to the validation of different warning scores, ${ }^{26}$ interprofessional as well as interdisciplinary application and practicability, we decided to use the National Early Warning Score 2 (NEWS2) by the Royal College of Physicians (RCP, London, England). ${ }^{7}$ With permission (final approval 4th September 2017, correspondence with C. Daley, editor, RCP), we translated the NEWS2 documents into German and pretested the questionnaire with an initial case series of five patients in a pilot study. ${ }^{8}$ After confirmation of the local independent ethics committee of Ulm University that no approval was required for this study (formal waiver, decision of 17th April 2018) and written informed consent by the participants, second-year and fifthyear students (in a 6-year curriculum of medicine, Ulm University, Germany) were interviewed in a paper-based questionnaire. The students were asked about vital signs in general and to comment on the clinical risk on a scale from 1 to 10 (1=no risk, $10=$ high risk), to set an appropriate monitoring frequency, and to define a clinical response for each fictional patient from the perspective of a ward physician. Because the NEWS2 was designed for a hospital setting outside of Germany and to allow students a certain margin of error, the answers considered as correct were set broader than in the NEWS2 (see legend of figure 2). In the context of this study, the students were not introduced to the NEWS2. Moreover, the students were asked to report whether they were taught in the application of EWS elsewhere. Paper-based questionnaires were created and processed using EvaSys Suite (Electric Paper Evaluationssysteme GmbH, Lüneburg, Germany). Data analyses and visualisation were performed with Excel 2019 (Microsoft, Redmond, Washington, USA) and Prism 8 (Graphpad, San Diego, California, USA).

\section{Patient and public involvement}

The survey was conducted on medical students of Ulm University, Germany, in the second and fifth year $(n=285$ । $290)$ with a response of $251(88.1 \%)$ । $267(92.1 \%)$. No patients were involved in this study.

\section{RESULTS}

Returned questionnaires were excluded when either two or more out of nine cases were not rated and the healthiest or the sickest fictional patient was rated vastly incorrect (indicative for insufficient understanding of the scale, e.g., rating the healthiest patient with a high clinical risk between 8 and 10) or if the informed consent to analyse the data was not given. In total, $15(6 \%)$ I 56 (21\%) files were omitted mostly due to an incomplete response resulting in 235 | 211 valid responses.
Students reported a wider range for normal oxygen saturation compared with the NEWS2 risk stratification (figure 1A). The lower limit for a physiological breathing rate was given below values that would lead to an increased NEWS2 score (figure 1B). Therefore, the classification of normal breathing parameters by students suggested a more conservative assessment of the impact of respiratory pathophysiology on patient risk compared with the NEWS2. Physiological levels of body temperature were given widely correct (figure 1C). The lower limit of systolic blood pressure (figure 1D) was specified below and the upper limit for the pulse rate was specified above the threshold for the NEWS2 to increase the score (figure 1E). The upper limit for normal systolic blood pressure was declared below the NEWS2 threshold, thus suggesting students more closely associated arterial hypertension with patient risk. Students reported a high confidence in interpreting oxygen saturation and pulse rate but felt less confident in interpreting respiration rate and level of consciousness (figure 1F).

Overall, no student stated previous experience with applying the NEWS2. However, $5.3 \%$ | $6.8 \%$ reported the usage of other EWSs prior to the survey. Students rated their skills in measuring vital signs on a nine-step Likert-like scale (1=observe to $9=$ teach others) higher $(7 \pm 4-8 \mid 8 \pm 7-8$, $\mathrm{p}<0.001)$ than their skills in interpreting those vital sign data with respect to the risk of patients $(4 \pm 3-6$ । $6 \pm 5-7$, $\mathrm{p}<0.001$ for second year vs fifth year, both Mann-Whitney test, figure $1 G)$. The vital signs of each fictional patient case are listed in figure $2 \mathrm{~A}$ with the case number referencing to the order on the paper questionnaire. Several students gave several responses regarding clinical risk evaluation, monitoring frequency, and response decisions that are shown in figure 2B-E. In general, students successfully identified patients being presumably healthy (case 5) or being at high risk (case 8), while they severely misjudged patients on the edge of certain thresholds (e.g., cases 1 and 2). In summary, second-year I fifth-year medical students chose an appropriate response in $66 \%(56 \%-78 \%)$ । $78 \%(67 \%-78 \%)$ of the nine presented cases. Strikingly, there was a low inverse or no correlation of the self-attributed proficiency to interpret vital sign with the successfully allocated cases regarding an appropriate clinical response for second-year medical students $(-0.33$, Spearman $r, \mathrm{p}<0.05)$ or fifth-year medical students $(-0.02$, Spearman $\mathrm{r}, \mathrm{p}=0.76)$, respectively.

\section{DISCUSSION}

To our best knowledge, this is the first study creating a level of knowledge measurement tool based on a highly validated EWS and applying it to future physicians as well as exploring possible sources of error. In this context, medical students in the role of a junior team member on the ward or tomorrow's physician play a key role to correctly assess each patient regarding his or her individual risk, to set up an appropriate monitoring frequency, and to allocate patients to proper care. While students overall correctly decided for a clinical response, there was still a considerable amount of overtreatment or undertreatment endangering patients 

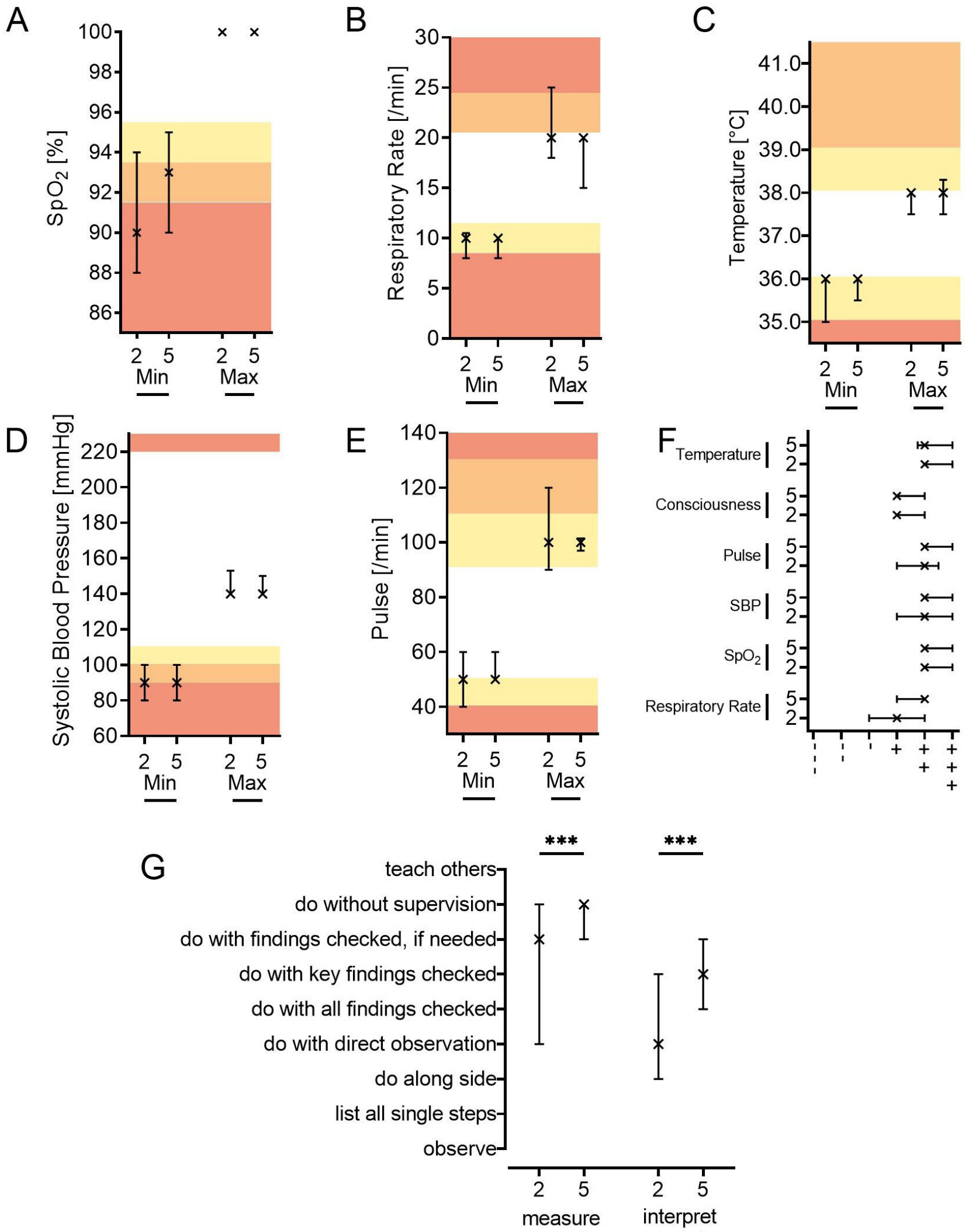

Figure 1 (A-E) Medical students in the second and fifth years were asked to list a threshold for the minimum and maximum value of the respective parameter, where they consider it to be altered in an adult. Colour scales are derived from the National Early Warning Score 2, where white indicates zero points, yellow one point, orange two points and red three points, respectively. (F) Students rated their proficiency to properly interpret an individual vital sign on a six-step Likert-type scale. (G) Self-reported proficiency to measure and interpret vital signs. Median $\pm|Q R, n=235| 211$, ${ }^{* * *}$ denotes $p<0.001$ for second year versus fifth year, both Mann-Whitney test. SBP, systolic blood pressure; $\mathrm{SpO}_{2}$, oxygen saturation. 


\begin{tabular}{|c|c|c|c|c|c|c|c|c|c|c|c|}
\hline $\begin{array}{l}\text { 岁 } \\
\text { 。 }\end{array}$ & 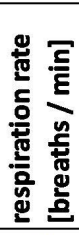 & 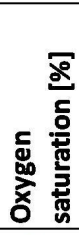 & 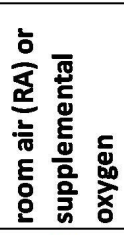 & 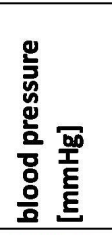 & 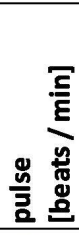 & 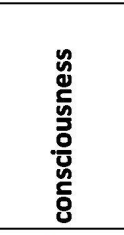 & 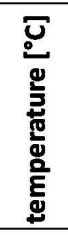 & 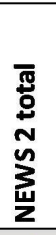 & 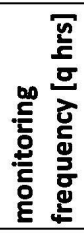 & 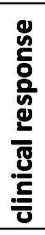 & 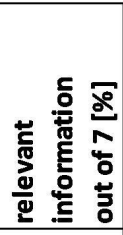 \\
\hline 5 & 15 & 99 & RA & $134 / 73$ & 63 & alert & 37.0 & 0 & 12 & 1 & $0 \%$ \\
\hline 1 & 20 & 96 & RA & $172 / 95$ & 53 & alert & 37.3 & 0 & 12 & 1 & $0 \%$ \\
\hline 9 & 13 & 98 & RA & $153 / 89$ & 105 & alert & 37.9 & 1 & $4-6$ & 2 & $14 \%$ \\
\hline 6 & 11 & 96 & RA & $103 / 59$ & 44 & alert & 36.2 & 3 & $4-6$ & 2 & $43 \%$ \\
\hline 3 & 21 & 96 & RA & $107 / 56$ & 82 & alert & 38.5 & 4 & 4-6 & 2 & $43 \%$ \\
\hline 4 & 16 & 98 & $\mathrm{RA}$ & $230 / 110$ & 53 & alert & 37.2 & 3 & 1 & 3 & $14 \%$ \\
\hline 7 & 23 & 95 & $\mathrm{RA}$ & $105 / 55$ & 93 & alert & 35.3 & 6 & 1 & 4 & $71 \%$ \\
\hline 2 & 22 & 99 & $\mathrm{RA}$ & $108 / 51$ & 95 & onfusion & 37.8 & 7 & $p$ & 5 & $57 \%$ \\
\hline 8 & 27 & 90 & $41 / \mathrm{min}$ & $85 / 38$ & 137 & pain & 39.7 & 19 & $p$ & 5 & $100 \%$ \\
\hline
\end{tabular}

C

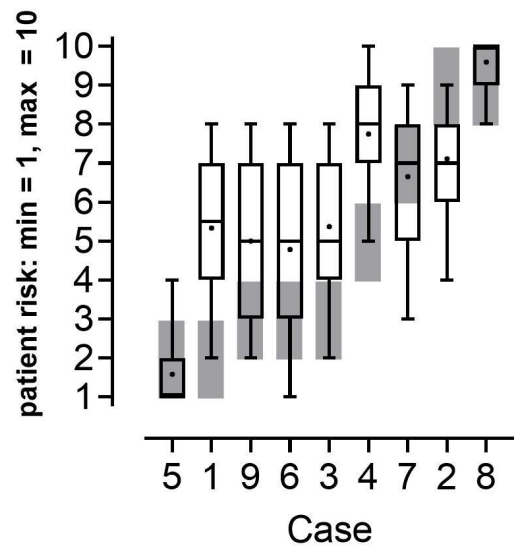

D

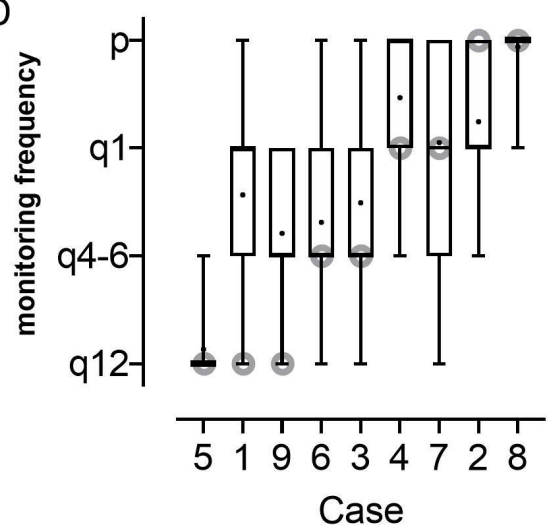

B

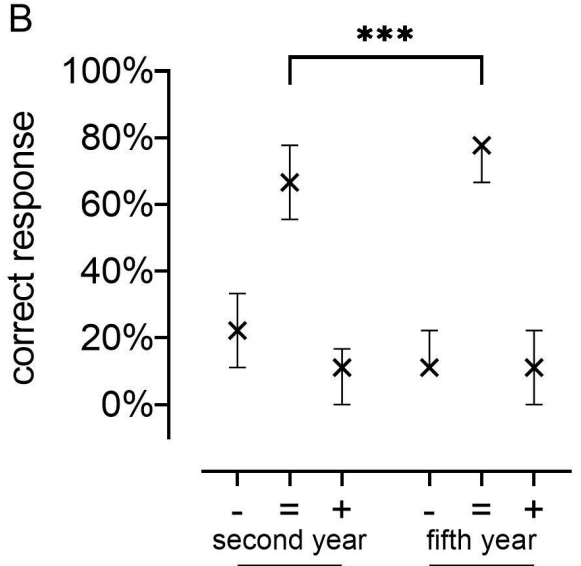

E

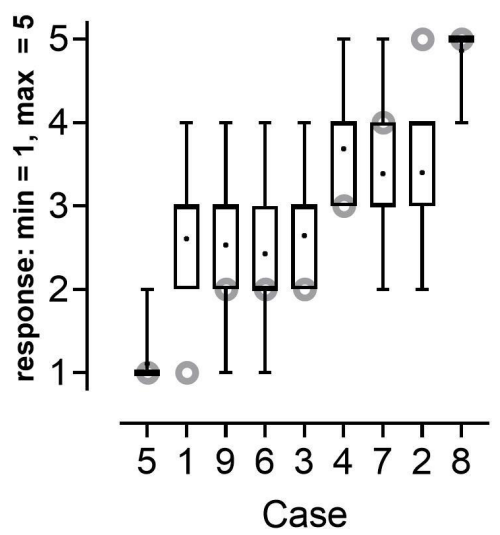

Figure 2 (A) Characteristics of the nine fictional patients and the responses considered as correct. (B) Percentage of cases that received an acceptable (=) response decision as indicated by the National Early Warning Score 2 (NEWS2) or an undertreatment (-) or an overtreatment (+), respectively. A response was considered to be acceptable when students chose the correct response decision or one higher. If the highest response decision was correct, the second highest response decision was also considered to be correct. (C-E) Risk stratification, set monitoring frequency ( $p=$ permanent, $q 12=e v e r y ~ 12$ hours) and clinical response by the fifth-year students (black) and correct response (grey). $n=235 \mid 211$, median \pm IQR with dots indicating the mean and whiskers indicating the $95 \%$ range in C-E. Responses in accordance to the NEWS2, ${ }^{7} 1=$ routine monitoring, $5=$ immediate transfer to a monitoring unit/intensive care unit.

and misallocating valuable resources like intensive care unit capacity. In this context, in septic shock, an early and prompt clinical response as well as a rapid initiation of treatment is 'vital' to improve survival significantly. ${ }^{9}$ A closer look to thresholds given by students for an individual vital sign gives hints concerning possible errors in the stratification process: For example, false-low assumptions of oxygen saturation and systolic blood pressure thresholds might explain the underestimation of certain cases. Moreover, this measurement tool might be useful to identify and to correct potentially dangerous false-high self-assessments for the competence in vital sign interpretations.

This study has limitations: First, there are several differences between the hospital setting in England (the origin of the NEWS2) and Germany (where the study took place), so some parts of the NEWS2 could only be transferred with limitations (e.g., education of nurses and physicians as well as ward management varies between the countries). Moreover, the assessment of a patient solely based on vital signs created an artificial situation that rarely occurs in clinical practice.
Of note, although the NEWS2 is widely validated, ${ }^{2-6}$ there is currently no reference success rate for the designed interview based on the used cases, for example, established by senior physicians. In addition, clinical professionals also had difficulties applying the NEWS2 properly and choosing an appropriate response, especially with increasing NEWS2 scores. ${ }^{10}$

\section{CONCLUSIONS}

Fifth-year medical students correctly decided in three out of four cases for an appropriate response based on vital signs. However, the deteriorating patient was especially at risk for deleterious undertreatment. The significance of moderately decreased oxygen saturation and systolic arterial blood pressure was often not recognised. Further studies need to collate and transfer these results to residents and senior physicians. To improve the risk stratification skills of future physicians, specific teaching units based on an established scoring system should be 
developed, tested, and, if a favourable educational impact can be demonstrated, implemented in medical curricula.

\section{Author affiliations}

${ }^{1}$ Institute of Anaesthesiologic Pathophysiology and Method Development, University Hospital UIm, Ulm, Baden-Württemberg, Germany

${ }^{2}$ Department of Anaesthesiology and Intensive Care Medicine, University Hospital Ulm, Ulm, Baden-Württemberg, Germany

${ }^{3}$ Institute of General Physiology, Ulm University, Ulm, Baden-Württemberg, Germany ${ }^{4}$ Medical Faculty, Office of the Dean of Studies, Ulm University, Ulm, Baden-

Württemberg, Germany

${ }^{5}$ Medical Faculty, Ulm University, Ulm, Baden-Württemberg, Germany

Contributors DM, MF, AH and PR conceptualised the study. DM, MF and PR collected the original data. DM, AS, OK and L-MM analysed the data. DM wrote the original draft of the manuscript. All authors contributed to the editing of the manuscript and read its final version.

Funding This study was financially supported by a research grant to DM provided by the 'AG Lehrforschung' (committee on medical educational research) of the Medical Faculty, Ulm University, Germany, and a rotation as clinician scientist to DM by the Collaborative Research Centre 1149, project number 251293561, German Research Foundation.

Competing interests None declared.

Patient and public involvement Patients and/or the public were not involved in the design, conduct, reporting or dissemination plans of this research.

Patient consent for publication Not required.

Ethics approval The local independent ethics committee (ethics committee of Ulm University) confirmed that no formal approval was required for this study (formal waiver, decision of $17^{\text {th }}$ April 2018). The participants were asked to give written informed consent prior to participation.

Provenance and peer review Not commissioned; externally peer reviewed.

Data availability statement All data relevant to the study are included in the article. All original data will be made available on reasonable request.

Open access This is an open access article distributed in accordance with the Creative Commons Attribution Non Commercial (CC BY-NC 4.0) license, which permits others to distribute, remix, adapt, build upon this work non-commercially, and license their derivative works on different terms, provided the original work is properly cited, appropriate credit is given, any changes made indicated, and the use is non-commercial. See: http://creativecommons.org/licenses/by-nc/4.0/.

\section{ORCID iD}

David Alexander Christian Messerer http://orcid.org/0000-0002-0834-038X

\section{REFERENCES}

1 Hogan H, Healey F, Neale G, et al. Preventable deaths due to problems in care in English acute hospitals: a retrospective case record review study. BMJ Qual Saf 2012;21:737-45.

2 Smith GB, Prytherch DR, Meredith P, et al. The ability of the National early warning score (news) to discriminate patients at risk of early cardiac arrest, unanticipated intensive care unit admission, and death. Resuscitation 2013;84:465-70.

3 Abbott TEF, Cron N, Vaid N, et al. Pre-Hospital national early warning score (news) is associated with in-hospital mortality and critical care unit admission: a cohort study. Ann Med Surg 2018;27:17-21.

4 Silcock DJ, Corfield AR, Gowens PA, et al. Validation of the National early warning score in the prehospital setting. Resuscitation 2015;89:31-5.

5 McGaughey J, O'Halloran P, Porter S, et al. Early warning systems and rapid response to the deteriorating patient in hospital: a systematic realist review. J Adv Nurs 2017;73:2877-91.

6 Jarvis S, Kovacs C, Briggs J, et al. Aggregate national early warning score (news) values are more important than high scores for a single vital signs parameter for discriminating the risk of adverse outcomes. Resuscitation 2015;87:75-80.

7 RCP. Royal College of physicians. National early warning score (news) 2: standardising the assessment of acute-illness severity in the NHS. updated report of a working Party. London: RCP, 2017. https://www. rcplondon.ac.uk/projects/outputs/national-early-warning-scorenews-2

8 Friz P, Horneffer A, Radermacher P. Vitalparameter - Trivial oder Tricky: Schlagen Studierende bei der Risikoabschätzung anhand von Vitalparametern den Würfel? Pilotstudie auf der Basis des National Early Warning Score 2 (NEWS2) [Bericht über Forschungsergebnisse]. Jahrestagung der Gesellschaft für Medizinische Ausbildung 2018.

9 Kumar A, Roberts D, Wood KE, et al. Duration of hypotension before initiation of effective antimicrobial therapy is the critical determinant of survival in human septic shock. Crit Care Med 2006;34:1589-96.

10 Kolic I, Crane S, McCartney S, et al. Factors affecting response to national early warning score (news). Resuscitation 2015;90:85-90. 